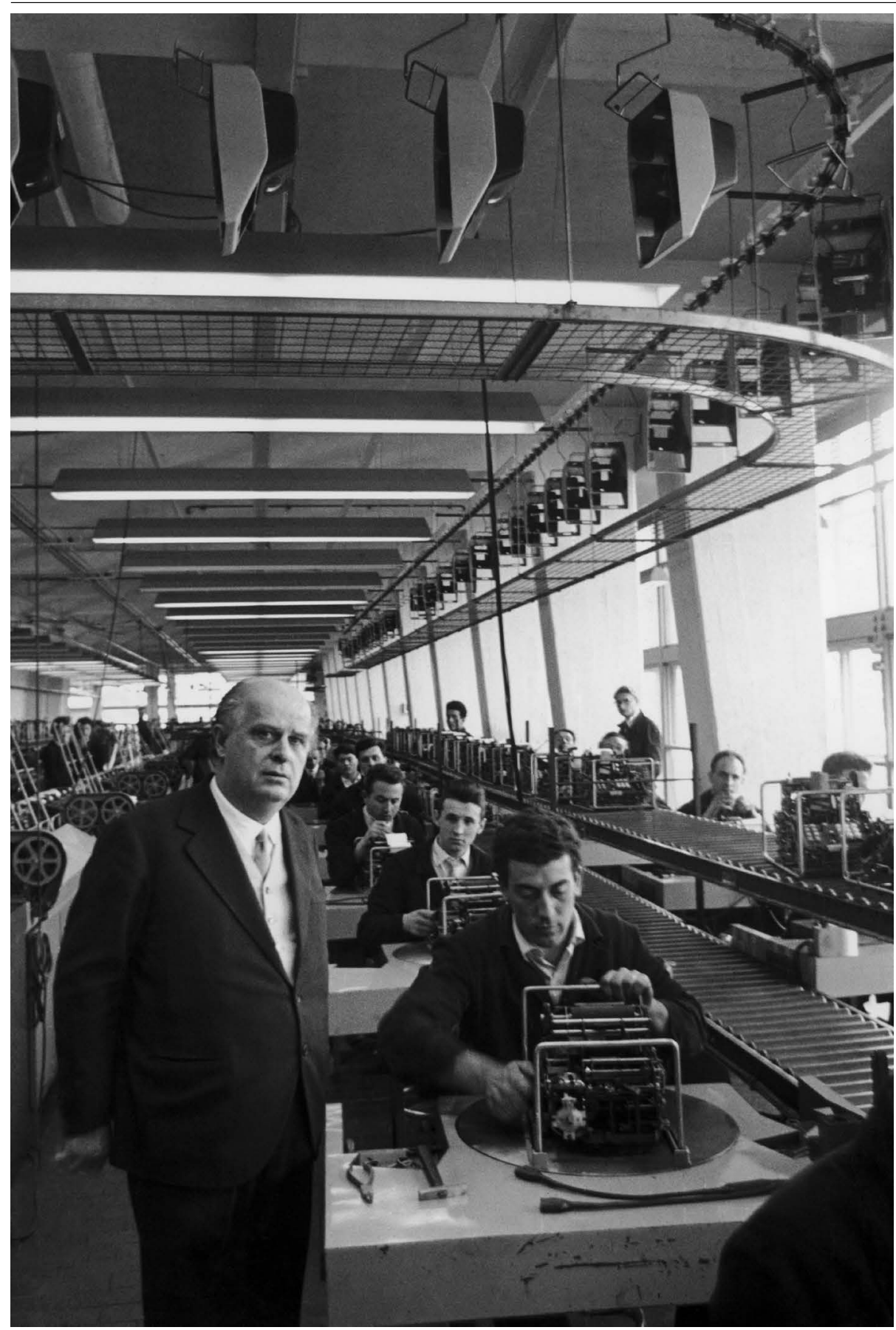

Engineer Adriano Olivetti in his typing machine factory in Ivrea, Italy.

\section{Turbulent birth of the personal computer}

\section{The strange circumstances surrounding the invention of the world's first PC are probed by a new book. By Sharon Weinberger}

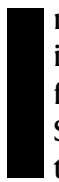
$\mathrm{n}$ the depths of the cold war, an Italian industrialist on the cusp of marketing the first personal computer dies on a train to Switzerland. Adriano Olivetti has had contact with Western spy agencies; his associates hint that his heart attack might not be what it seems. Such is the thriller-esque start to biographer Meryle Secrest's The Mysterious Affair at Olivetti.

At the heart of Secrest's book lie two questions: how did the Italian typewriter company Olivetti produce the world's first PC in the 1960s - long before its competitors - only to have its work fall into obscurity? And could Adriano Olivetti's death be linked to the company's disappearance from computer history? Secrest weaves a startling narrative around these events, involving a US intelligence agency and an information-technology multinational.

The story goes back to Camillo Olivetti, the Jewish-Italian industrialist who founded the company in Ivrea, Piedmont, in 1908. His visionary son Adriano, who succeeded him as company head in 1938, was interested in architecture, politics and technology. He began to look beyond typewriters to machines combining the best aspects of form and function. More crucially, he started to expand from mechanical typewriters into electronics.

When the Second World War broke out, Adriano Olivetti paid lip service to the fascists while secretly working to remove prime minister Benito Mussolini, all while keeping his factory going and his family alive. He survived the war, the company thrived, and he opened an electronics laboratory that drew on his experience in the United States. In the late 1950s, the company created one of the world's first transistorized mainframes, the ELEA 9003.

Olivetti's death in 1960 threatened to derail the plans he had set out for the company to further expand into computers. Moreover, the firm was in a downward spiral, following his decision in 1959 to buy his main competitor, the US typewriter firm Underwood. Yet Mario Tchou, a key engineer who oversaw the company's electronics work, was already thinking about shrinking mainframes into something that could sit on a desk. Adriano's talented but less savvy son Roberto oversaw manufacturing of the Programma 101 (P101) desktop computer, which made its debut in 1965. It was the world's first PC, and sold an astonishing 44,000 units over several years, including some to NASA. But the company's computer manufacturing was eventually overtaken by its competitors, particularly in the United States.

That sounds like the guts of a great technology history. The book's subtitle, meanwhile, promises spy-versus-spy intrigue involving the CIA and US computer giant IBM. However, Secrest focuses more on the Olivetti family than its products. There is a bare-bones description of the P101 and how it was developed: the 


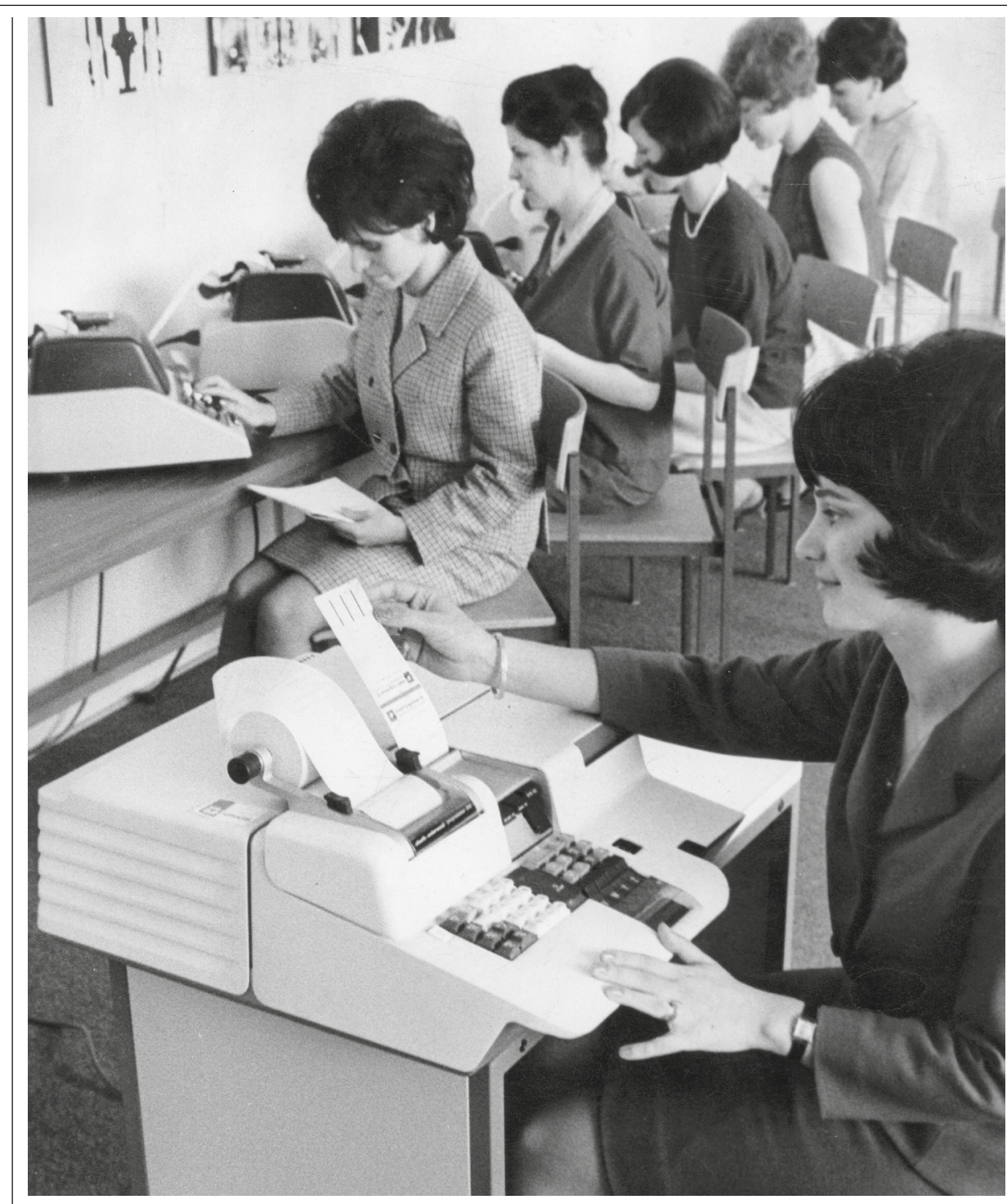

Olivetti's table-top computer, 'Programma 101' in 1966.

programming system, Secrest notes, “took an enormous amount of experimentation". But there is little more on what must be an intriguing techie history.

Secrest thus also misses several opportunities to tease out intriguing storylines. For example, Adriano Olivetti's insistence that something sitting in your office should be both functional and beautiful almost certainly inspired Apple co-founder Steve Jobs. The aesthetic similarities between Olivetti's 1960s-era showroom on Fifth Avenue in New York City and today's iconic Apple stores are uncanny.

The book's treatment of espionage is at times more detailed than its take on tech. Secrest describes fascinating wartime contacts between Adriano Olivetti and British and US intelligence agencies. While feigning loyalty to the Fascist Party, the industrialist was secretly meeting with the US Office of Strategic Services (OSS), the predecessor to the CIA, which dubbed him 'Agent 660'. There is drama in this. But as Secrest makes clear, Adriano was no 007; the OSS never acted on his plans, and
British intelligence seemed to dismiss him as a dreamer and deemed his convoluted scheme for toppling Mussolini unrealistic.

The narrative takes a stranger turn around Adriano Olivetti's death. It seems plausible that, saddled with mounting debt and Underwood's outdated factories, a 58-year-old businessman might die of a heart attack. Instead, Secrest decides that the CIA murdered Olivetti - as well as Tchou, who died in a car accident in 1961.

Gaining access to CIA records is certainly arduous, and Secrest describes her unsuccessful attempt to meet with the agency's historian, David Robarge. In the absence of insider insights

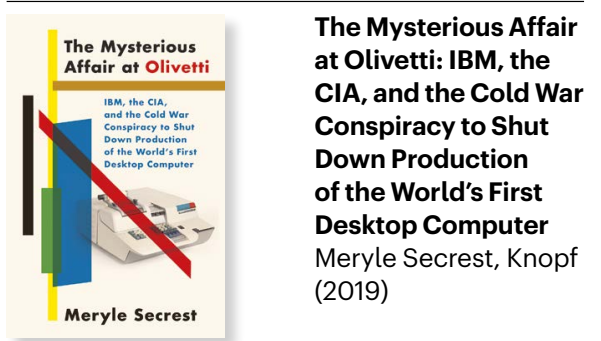

or access to fresh archival records, she turns to a car-repair shop owner in Rockville, Maryland, for confirmation of her theory that the CIA engineered the car accident that killed Tchou.

The CIA, of course, really has attempted to assassinate certain figures, such as Patrice Lumumba, the first prime minister of the Democratic Republic of the Congo. But Secrest presents no evidence that US spies were involved in Olivetti's death. She implies that IBM, too, was somehow implicated, citing cold-war competition and the company's work for the US government and intelligence. (She reminds us that IBM, as documented by Edwin Black in his 2001

\section{“A more interesting historical question is why US computer science advanced so quickly during the cold war."}

book IBM and the Holocaust, sold technology to the Nazis in the 1930s.) A link between that and the Olivetti affair is never aired, however.

This conspiracy-mongering is a shame. Secrest does all the right research, and the clues to the company's troubles (and Olivetti's woes) are right in front of her. In an era of rampant conspiracy theories, such as bizarre allegations involving the Jewish Hungarian-American billionaire George Soros, we rely on scholarship to pull out the facts, not just the speculation.

A more interesting historical question is why US computer science advanced so quickly during the cold war, leaving Europe behind for decades. It's likely that this happened because the Pentagon and US intelligence agencies invested in companies and technologies that had no immediate commercial prospects, but served US strategic interests (see page 481). The relationship between spies, soldiers and computer scientists during and after the second half of the twentieth century is worthy of serious exploration. The Mysterious Affair at Olivetti does not offer that.

Yet this book is, in other ways, a laudable attempt. It shines when describing Adriano Olivetti's interest in architecture (Secrest authored the 1992 book Frank Lloyd Wright: A Biography). Secrest writes well on the aesthetics of Olivetti machines and Adriano's attraction "to clean, boxy lines", the signature of the Bauhaus movement. Her biographer's instinct - choosing a visionary figure whose contributions have not been fully appreciated - is also to be applauded. As she laments, "the Programma 101 has not been well served by computer historians on or off the Internet." She is right. That record remains to be filled.

Sharon Weinberger is the author of The Imagineers of War: The Untold Story of DARPA, the Pentagon Agency That Changed the World. e-mail: sharonweinberger@gmail.com 